\title{
Discriminação por Gênero no Mercado de Trabalho Local: um Estudo para os Municípios do Rio Grande do Sul
}

\section{Discrimination by Gender in the Local Labour Market: a Study for the Municipalities of the Rio Grande do Sul}

\author{
Rafael Mesquita Pereira* \\ Cristiano Aguiar de Oliveira**
}

\begin{abstract}
Resumo: O objetivo deste artigo é analisar o diferencial de rendimentos entre homens e mulheres nos principais municípios das sete mesorregiões do Rio Grande do Sul. Para tanto, tomando por base os dados do Censo 2010, realiza-se a decomposição do diferencial de rendimentos por gênero, utilizando o procedimento de Oaxaca-Blinder com a inclusão de controles para os setores (atividades econômicas) dos municípios analisados. Dessa forma, é possível verificar se a magnitude do diferencial de rendimentos entre os gêneros é explicada pelas diferenças de atributos produtivos dos indivíduos, pela alocação entre os setores de atividade econômica, pelas características do mercado de trabalho dos municípios ou por fatores relacionados à discriminação. Os resultados mostram que, embora as mulheres possuam maiores atributos produtivos que os homens, elas recebem menores rendimentos do trabalho, mesmo quando se realizam controles para a alocação nas atividades e para mercados de trabalho locais, fato esse que apresenta evidências suficientes para a existência discriminação estatística contra as mulheres em todos os municípios analisados.
\end{abstract}

Palavras-chave: Decomposição de Oaxaca-Blinder. Discriminação. Municípios.

Abstract: The objective of this paper is to analyze the difference in income between men and women in the main municipalities of the seven mesoregions of Rio Grande do Sul. Therefore, from the 2010 Census database, the decomposition of the gender earnings differential is obtained using the Oaxaca-Blinder procedure with the addition of controls for the sectors (economic activities) of the analyzed municipalities. This procedure allows checking whether the magnitude of the wage difference between the genders is explained by differences in productive attributes of individuals, in the allocation between sectors of economic activity, in the characteristics of the labor market of the municipalities or by factors related to discrimination. The results show that although women have greater productive attributes than men, they receive lower wages, even when controls for the allocation in the activities and for local labor markets are included, a fact that provides sufficient evidence for the existence of statistical discrimination against women in all analyzed municipalities.

Keywords: Oaxaca-Blinder decomposition. Discrimination. Municipalities.

* Doutorando em Economia Aplicada pela Escola de Agricultura "Luiz de Queiroz" (ESALQ) da Universidade de São Paulo (USP). Professor assistente da Universidade Federal do Rio Grande (Furg). E-mail: rafaelmesquita@furg.br

* $\quad$ Doutor pela Universidade Federal do Rio Grande do Sul (UFRGS). Professor adjunto da Universidade Federal do Rio Grande (Furg). E-mail: cristiano.oliveira@furg.br 
JEL Classification: J24; J71; R23.

\section{Introdução}

Atualmente, é notório o espaço que a mulher conquistou no mercado de trabalho. O reconhecimento de suas capacidades e habilidades vem credenciando-as para ocupar cargos importantes, os quais, num passado recente, a elas não eram destinados. Hoje, é comum a presença de mulheres liderando grandes corporações e exercendo comando em ambientes de trabalho. Do ponto de vista social, essa quebra de paradigma possui grande relevância, uma vez que está pondo fim a uma barreira cultural que colocava homens e mulheres em patamares diferentes, não por uma avaliação relacionada à produtividade, mas pela segregação que havia no que se refere ao gênero.

Esta conquista de espaço pelas mulheres não parece dar sinais de arrefecimento no Brasil, já que, nos últimos anos, é visível o crescimento da participação feminina na força de trabalho. Por exemplo, nos anos 1970, segundo dados do Instituto Brasileiro de Geografia e Estatística (IBGE), a participação feminina correspondia a 20,86\%. Já nos anos 1990, essa taxa atingia 35,56\% (JACINTO, 2005) e, no final da última década, representava a maioria da força de trabalho, com $51,33 \%$ dos trabalhadores.

No Rio Grande do Sul, embora mais de $45 \%$ do mercado de trabalho seja ocupado por mulheres, ainda hoje elas recebem remunerações inferiores no mercado de trabalho, quando comparadas com as dos homens. O que tem chamado a atenção dos pesquisadores que estudam os diferenciais de rendimentos é o fato de indivíduos igualmente produtivos serem diferentemente avaliados no mercado de trabalho, com base em atributos não produtivos, caracterizando, assim, a existência de discriminação nesse mercado (CAVALIERI; FERNANDES, 1998).

Na literatura econômica, uma série de trabalhos, como o de Camargo e Serrano (1983), Barros, Ramos e Santos (1995), Cavalieri e Fernandes (1998), Leme e Wajnman (2001), Giuberti e Menezes-Filho (2005), Scorzafave e Pazello (2007) e Cambota e Marinho (2007), com a utilização de informações da Pesquisa Nacional por Amostra de Domicílios (PNAD) ou da Relação Anual de Informações Sociais (RAIS), indicam que as mulheres estão recebendo menores salários que os homens no mercado de trabalho e que isso está atrelado a questões discriminatórias e não de produtividade. Recentemente, Stein, Sulzbach e Bartels (2015) realizaram um estudo semelhante ao proposto neste trabalho, também para o Rio Grande do Sul, porém com informações da PNAD, contribuindo com resultados adicionais aos que aqui serão apresentados.

Neste contexto, o objetivo deste artigo é identificar a existência de diferencial de rendimentos entre homens e mulheres nos principais municípios das sete mesorregiões do Rio Grande do Sul. Para tanto, inicialmente, estima-se uma equação 
de rendimentos tal como proposta por Mincer (1974) com correção para viés de autosseleção (Modelo de Heckman) e se faz uma decomposição do diferencial dos rendimentos por gênero, usando como ferramenta o procedimento de Oaxaca-Blinder. Este último visa, também, constatar se esse diferencial está atrelado a características produtivas dos indivíduos ou a componentes que caracterizam a existência de discriminação entre gêneros.

O trabalho se diferencia dos existentes por dar um enfoque local a um tema que, normalmente é tratado com dados nacionais e estaduais; todavia, peculiaridades nos mercados de trabalho de municípios, tais como a presença de externalidades e aglomeração de atividades em alguns setores, justificam a necessidade de estudos locais. Por exemplo, um homem e uma mulher com características idênticas no que se refere ao ato laboral num mesmo setor podem obter remunerações distintas por atuarem em mercados de trabalho distintos. Cada município possui um mercado de trabalho próprio, que pode sofrer influências de externalidades positivas, tais como economias de aglomeração.

Segundo Gordon e McCann (2000), mercados de trabalho locais podem ter ganhos de eficiência devido à aglomeração de trabalhadores de um setor em uma mesma região, assim eles podem trocar de empresas a um baixo custo, uma vez que não precisam mudar o local de sua residência. Nesses casos, as empresas também são beneficiadas, pois podem contratar trabalhadores treinados por outras empresas. Além disso, trabalhadores de empresas vizinhas podem trocar informações de maneira formal e informal a respeito de novos produtos e de novas tecnologias. A simples observação do comportamento de empresas vizinhas pode levara um processo de aprendizagem, que inclui a observação dos processos que obtêm sucesso no mercado, quais trabalhadores devem ser contratados, de quem se deve comprar e para quem se deve vender etc. (MCCANN, 2001). Como este conhecimento é adquirido sem qualquer forma de pagamento e reflete em maiores lucros para as empresas e maiores remunerações para os trabalhadores, é uma externalidade positiva, que pode ser fonte de uma heterogeneidade não observada que dados agregados por estados podem não ser capazes de controlar. Portanto, um diferencial do presente estudo é a utilização de informações do Censo de 2010, realizado pelo IBGE, que permitem não só a desagregação por municípios, mas também trabalhar com uma amostra bastante representativa do mercado de trabalho local, algo que não é possível de ser realizado, por exemplo, com informações da PNAD.

Além desta introdução, o artigo está organizado da seguinte maneira: a próxima seção refere-se à economia da discriminação; a terceira seção apresenta brevemente a metodologia; a quarta seção é referente à análise descritiva das informações utilizadas; a quinta seção apresenta os resultados obtidos por meio da estimação da equação de rendimentos do trabalho para o Rio Grande do Sul e 
para os municípios analisados, seguidos da decomposição do diferencial de rendimentos entre os gêneros. Ao final do artigo, são apresentadas considerações finais.

\section{Economia da Discriminação}

A discriminação no mercado de trabalho vem sendo objeto de estudos há algum tempo, buscando explicar os fatores que determinam sua existência. $\mathrm{Na}$ economia, esta vem sendo entendida como uma diferenciação ou distinção entre indivíduos com uma característica pejorativa. Na visão de Loureiro (2003), essa prática é ineficiente em uma economia competitiva, uma vez que os indivíduos alvos da discriminação recebem uma remuneração menor do que seu produto marginal, gerando salários desiguais, tratamento diferenciado e segregação.

No que diz respeito aos tipos de discriminação identificados no mercado de trabalho, pode-se dizer que, a partir da análise de Loureiro (2003), eles se classificam em quatro tipos básicos: discriminação salarial, discriminação de emprego, discriminação de trabalho ou ocupacional e discriminação ao acesso de capital humano. A discriminação salarial ocorre quando trabalhadores de um grupo recebem menores salários do que outro grupo de trabalhadores que exercem o mesmo tipo de atividade. Já a discriminação de emprego ocorre quando os grupos considerados minoritários estão em desvantagem no mercado de trabalho por causa da baixa oferta de empregos, sendo, dessa forma, os mais atingidos. A discriminação de trabalho ou ocupacional ocorre quando os grupos minoritários são arbitrariamente restringidos ou proibidos de exercer ou ocupar certas funções, mesmo quando sejam considerados aptos. Por último, a discriminação ao acesso de capital humano consiste nas menores oportunidades que determinados grupos possuem de aumentarem a sua produtividade, como por exemplo, educação formal e treinamento.

Nesse contexto, os economistas elaboraram teorias as quais buscam entender melhor a discriminação, dando origem à teoria econômica da discriminação. O trabalho de Becker (1957) foi uma das contribuições pioneiras a essa teoria. O autor partiu do pressuposto de que existem preferências em descriminar incorporadas à função de utilidade dos agentes, de modo que, em um mercado competitivo, estes possuam preferências diferentes e possam agir de acordo com tais preferências. Essas preferências podem ocorrer de três maneiras: discriminação do empregador, discriminação do empregado e discriminação do consumidor. Assim, o indivíduo que prefere discriminar estaria disposto a pagar alguma coisa para manter o preconceito de algum tipo, seja por redução de lucros, salários ou até renda.

Mais adiante, surgiram os modelos de discriminação estatística, nos quais se destacam os estudos de Phelps (1972), Arrow (1973) e Aigner e Cain (1977). Eles 
surgem a partir do problema de informação imperfeita, ou seja, pelos problemas que existem em se obter informações sobre o potencial e produtividade do indivíduo. Conforme destaca Jacinto (2005), a incerteza leva o empregador a utilizar as estatísticas sobre a performance média do grupo ao qual pertence cada candidato para prever sua produtividade. Dessa forma, o candidato que pertence ao grupo com maior produtividade poderia se beneficiar e isso geraria uma discriminação estatística.

Segundo Loureiro (2003), os modelos de discriminação por preferência e estatística diferem basicamente no seguinte aspecto: o primeiro será sempre ineficiente, enquanto que o segundo poderá ser tanto eficiente quanto ineficiente. A ineficiência da discriminação por preferências constata-se no tratamento diferenciado ou nos salários diferentes que indivíduos com a mesma produtividade recebem no ambiente de trabalho. Já a discriminação estatística pode ser eficiente por não envolver preferência em discriminar. Entretanto, é ineficiente quando o empregador sabe que, em média, dois grupos de trabalhadores possuem produtividades esperadas iguais, mas como possui menos informações a respeito de um dos grupos, acaba por pagar salários diferentes aos trabalhadores.

Analisando-se, em particular, a discriminação realizada pelo empregador, observa-se que, para ele, o comportamento discriminador está inversamente relacionado aos lucros de sua firma. Isso ocorre porque, ao agir dessa maneira, o empregador demonstra estar disposto a pagar, direta ou indiretamente, na forma de uma redução de lucros, pela preferência por algum grupo em detrimento de outro. Em um mercado competitivo, essa situação não é sustentável porque as firmas que não discriminam teriam vantagens ao contratar os trabalhadores discriminados, oferecendo-lhes menores salários quando comparados aos pagos pelas firmas discriminadoras. Por esta razão, trata-se de uma situação que não deveria perdurar por muito tempo (JACINTO, 2005).

Este artigo visa identificar a existência de discriminação estatística e, assim, verificar se indivíduos de gêneros diferentes e que possuem os mesmos atributos produtivos são diferentemente remunerados nos mercados de trabalho analisados de alguns municípios gaúchos. Para o alcance dos resultados, será apresentada na próxima seção a metodologia utilizada para a mensuração da discriminação nos municípios integrantes deste estudo. Num primeiro momento, será abordado o Modelo Heckman, utilizado para a estimação da equação de rendimentos do trabalho considerando os problemas de autosseleção. Uma vez analisados os rendimentos dos indivíduos, parte-se para a estimação da decomposição de Oaxaca-Blinder, porque esta fornecerá as informações necessárias para a verificação da existência - ou não - da discriminação estatística. 


\section{Metodologia}

Para a estimação da equação de rendimentos do trabalho, será utilizado o modelo desenvolvido por Heckman (1979), visando corrigir possíveis problemas de seleção amostral existentes neste tipo de situação. Segundo o autor, este viés de seleção de amostra pode surgir, na prática, por duas razões. Primeiro, pode haver autosseleção por parte dos indivíduos ou unidades de dados que estão sendo investigados. Em segundo lugar, as decisões de seleção de amostra por analistas ou processadores de dados funcionam praticamente da mesma maneira que uma autosseleção.

Sendo assim, o Modelo de Seleção Amostral desenvolvido por Heckman (1979) é considerado o mais adequado para estimar as equações de rendimentos do tipo mincerianas, pois corrige o problema de viés de seleção amostral que a estimação por Mínimos Quadrados Ordinários (MQO) normalmente apresenta.

Para solucionar o problema de viés de seleção das informações, Heckman (1979) propôs um modelo de duas equações, incluindo características pessoais dos indivíduos, avaliando os fatores que determinam a participação ou não destes no mercado de trabalho para, logo após, estimar uma segunda equação referente aos rendimentos destes indivíduos que participam do mercado mencionado.

O modelo de seleção amostral proposto por Heckman (1979) parte da equação de rendimentos do trabalho (salários) dada por:

$$
\mathrm{W}_{\mathrm{i}}=\mathrm{x}_{\mathrm{i}}^{\prime} \beta+\varepsilon_{\mathrm{i}}
$$

onde $\mathrm{W}_{\mathrm{i}}$ é o salário, $\mathrm{x}_{\mathrm{i}}^{\prime}$ representa as variáveis observadas relacionadas à produtividade do iésimo indivíduo, e $\varepsilon_{\mathrm{i}}$ é um termo de erro. W é observado apenas para os trabalhadores, ou seja, apenas as pessoas que recebem algum tipo de remuneração por seu trabalho. Dessa forma, segundo Cameron e Trivedi (2005), a participação na amostra pode ser representada da seguinte forma:

$$
W_{1 i}=\left\{\begin{array}{l}
1 \text { se } W_{1 i}^{*}>0 \\
0 \text { se } W_{1 i}^{*} \leq 0
\end{array}\right.
$$

o que resulta na seguinte equação sujeita ao truncamento:

$$
W_{2 i}=\left\{\begin{array}{c}
W_{2 i}^{*} \text { se } W_{1 i}^{*}>0 \\
\text { se } W_{1 i}^{*} \leq 0
\end{array}\right.
$$

Ainda, de acordo com Cameron e Trivedi (2005), esse modelo especifica que $\mathrm{W}_{2}$ é observado quando $\mathrm{W}_{1}{ }^{*}>0$, de modo que $\mathrm{W}_{2}$ não precisa ter qualquer valor significativo quando $\mathrm{W}_{1}{ }^{*} \leq 0$. Dessa forma, para $u \mathrm{~W}_{2}$ positivo, a densidade ob- 
servada é $f^{\prime}\left(W_{2}^{*} \mid W_{1}^{*}>0\right) \times \operatorname{Pr}\left[W_{1}^{*}>0\right]$. Então, a equação de seleção tem a seguinte função de verossimilhança:

$$
L=\prod_{i=1}^{n}\left\{\operatorname{Pr}\left[W_{1 i}{ }^{*} \leq 0\right]\right\}^{1-W 1 i}\left\{f\left(W_{2}{ }^{*} \mid W_{1 i}{ }^{*}>0\right) \times \operatorname{Pr}\left[W_{1 i}{ }^{*}>0\right]\right\}^{W_{1 i}}
$$

onde o primeiro termo é a contribuição discreta quando $W_{1 i}{ }^{*} \leq 0$, uma vez que $W_{1 i}=0$, e o segundo termo é a contribuição contínua quando $W_{1 i}>0$.

Realizada esta primeira etapa, parte-se para a estimação de fato da equação de rendimentos, utilizando o método de Mínimos Quadrados Ordinários. Conforme destacam Cirino e Lima (2010), essa equação é formulada a partir da teoria do capital humano, incluindo algumas outras variáveis com o intuito de controlar as diferenças de rendimentos derivadas de setores de atividades, posição e tipo de ocupação, além da inserção no mercado de trabalho. Assim, torna-se possível obter uma medida mais adequada das diferenças de rendimentos entre os gêneros, objetivo central deste trabalho.

O procedimento de Heckman, em dois estágios, aumenta a regressão por Mínimos Quadrados Ordinários através de uma estimativa do regressor omitido $\lambda_{1}\left(z_{i}^{\prime} \gamma\right)$. Assim, usando os valores positivos de $\mathrm{W}_{2}$, a estimativa por MQO do modelo é:

$$
\mathrm{W}_{2 \mathrm{i}}=\mathrm{x}_{2 \mathrm{i}}{ }^{\prime} \beta_{2}+\sigma_{12} \lambda\left(\mathrm{x}_{1 \mathrm{i}} \hat{\beta}^{\prime}\right)+\varepsilon_{\mathrm{i}}
$$

onde $\varepsilon$ é um termo de erro, $\hat{\beta}_{1}$ é o coeficiente obtido através do primeiro estágio da regressão Probit de $W_{1}$ em $x_{1}$, uma vez que $\operatorname{Pr}\left[W_{1 i}{ }^{*}>0\right]=\varphi\left(x_{1}{ }^{\prime} \beta_{1}\right)$, e $\lambda\left(x_{1}{ }^{\prime} \hat{\beta}_{1}\right)=\varphi\left(x_{1}\right.$, $\left.\hat{\beta}_{1}\right) / \Phi\left(\mathrm{x}_{1}^{\prime} \hat{\beta}_{1}\right)$ é o inverso da razão de Mills estimada. Essa regressão não fornece diretamente uma estimativa de $\sigma_{2}{ }^{2}$. Então, por se tratar de uma variância truncada, ${ }^{1}$ estima-se $\hat{\sigma}_{2}^{2}=\mathrm{N}^{-1} \sum_{\mathrm{i}}\left[\hat{\varepsilon}_{\mathrm{i}}^{2}+\sigma_{12}^{2} \hat{\lambda}_{\mathrm{i}}\left(\mathrm{x}_{1}^{\prime} \hat{\beta}_{1}+\hat{\lambda}_{\mathrm{i}}\right)\right]$, onde $\hat{\varepsilon}$ é o resíduo da estimação por MQO da equação $\mathrm{W}_{2 \mathrm{i}}=\mathrm{x}_{2 \mathrm{i}}{ }^{\prime} \beta_{2}+\sigma_{12} \lambda\left(\mathrm{x}_{1 \mathrm{i}}{ }^{\prime} \hat{\beta}_{1}\right)+\varepsilon_{\mathrm{i}}$ e $\hat{\lambda}_{\mathrm{i}}=\lambda\left(\mathrm{x}_{\mathrm{Ii}}{ }^{\prime} \hat{\beta}_{1}\right)$. A correlação entre os dois erros ${ }^{2}$ pode, em seguida, ser estimada através de $\hat{\rho}=\hat{\sigma}_{12} / \hat{\sigma}_{2}$.

O estimador de $\beta_{2}$ obtido através deste procedimento em dois estágios é consistente (CAMERON; TRIVEDI, 2005). Apesar de uma perda de eficiência em comparação com o estimador de máxima verossimilhança sob normalidade conjunta dos erros, os quais podem ser bastante grandes, esse estimador é muito popular pelas seguintes razões: é simples de implementar, sua abordagem é aplicável a uma gama de modelos de seleção e o estimador requer suposições distribucionais mais fracas do que a normalidade conjunta de $\varepsilon_{1}$ e $\varepsilon_{2}$.

$\overline{\mathrm{V}\left[\mathrm{W}_{2} \mid \mathrm{X} . \mathrm{W}_{1}{ }^{*}>0\right]}=\sigma_{2}^{2}-\sigma_{12}^{2} \lambda\left(\mathrm{x}_{1}^{\prime} \beta_{1}\right)\left(\mathrm{x}_{1}^{\prime} \beta_{1}+\lambda\left(\mathrm{x}_{1}^{\prime} \beta_{1}\right)\right.$

2 De acordo com Cameron e Trivedi (2005), a estimação por máxima verossimilhança é simples, dada a abordagem adicional, na qual erros correlacionados são conjuntamente normalmente distribuídos e homocedásticos, com $\left[\begin{array}{l}\varepsilon_{1} \\ \varepsilon_{2}\end{array}\right] \sim N\left[\left[\begin{array}{l}0 \\ 0\end{array}\right] \cdot\left[\begin{array}{cc}1 & \sigma_{12} \\ \sigma_{12} & \sigma_{2}^{2}\end{array}\right]\right.$. Como se trata de um modelo Probit, a normalização $\sigma_{1}^{2}=1$ é apenas utilizada desde que $\mathrm{W}_{1}{ }^{2 *}$ seja observado. 
Para a realização do exercício contrafactual será utilizada a decomposição desenvolvida por Oaxaca (1973) e Blinder (1973). Segundo os autores, sejam dois grupos, homens (A) e mulheres $(B)$, uma variável $Y$ (que representa o (log) dos rendimentos) como a variável rendimento e um conjunto de preditores que representam os indicadores de capital humano, tais como educação e experiência no trabalho. A magnitude da diferença média dos rendimentos entre os dois grupos pode ser representada da seguinte forma (JAHN, 2008):

$$
R=E\left(Y_{A}\right)-E\left(Y_{B}\right)
$$

onde $E(Y)$ representa o valor esperado dos rendimentos do trabalho, o qual é contabilizado através das diferenças entre os grupos nos preditores.

Baseado em um modelo linear

$$
\mathrm{Y}_{1}=\mathrm{X}_{1}^{\prime} \beta_{1}+\varepsilon_{1}, \mathrm{E}\left(\varepsilon_{1}\right)=0,1 \in\{\mathrm{A} \text { e B }\}
$$

onde $\mathrm{X}$ é um vetor contendo os preditores e uma constante, $\beta$ contém os parâmetros de inclinação e o intercepto, e $\varepsilon$ é o erro. A diferença média de rendimentos pode ser expressa como a diferença na predição linear na média dos regressores do grupo específico, representada como:

$$
\mathrm{R}=\mathrm{E}\left(\mathrm{Y}_{\mathrm{A}}\right)-\mathrm{E}\left(\mathrm{Y}_{\mathrm{B}}\right)=\mathrm{E}\left(\mathrm{X}_{\mathrm{A}}\right)^{\prime} \beta_{\mathrm{A}}-\mathrm{E}\left(\mathrm{X}_{\mathrm{B}}\right)^{\prime} \beta_{\mathrm{B}}
$$

uma vez que $\mathrm{E}\left(\mathrm{Y}_{\mathrm{l}}\right)=\mathrm{E}\left(\mathrm{X}_{1}^{\prime} \beta_{1}+\varepsilon_{1}\right)=\mathrm{E}\left(\mathrm{X}_{1}^{\prime} \beta_{\mathrm{l}}\right)+\mathrm{E}\left(\varepsilon_{1}\right)=\mathrm{E}\left(\mathrm{X}_{\mathrm{l}}\right)^{\prime} \beta_{1}, \mathrm{E}(\beta \mathrm{l})=\beta_{1}$ e $\mathrm{E}\left(\varepsilon_{1}\right)=0$ por suposição.

Conforme Jann (2008), uma decomposição alternativa, que é proeminente na literatura de discriminação, resulta do conceito de que há algum vetor de coeficientes não discriminatórios que deve ser usado para determinar a contribuição de diferenças nos preditores. A diferença de rendimentos pode, então, ser escrita da seguinte forma:

$$
\mathrm{R}=\left[\mathrm{E}\left(\mathrm{X}_{\mathrm{A}}\right) \mathrm{E}\left(\mathrm{X}_{\mathrm{B}}\right)\right]^{\prime} \beta^{*}+\left[\mathrm{E}\left(\mathrm{X}_{\mathrm{A}}\right)^{\prime}\left(\beta_{\mathrm{A}}-\beta^{*}\right)+\mathrm{E}\left(\mathrm{X}_{\mathrm{B}}\right)^{\prime}\left(\beta_{\mathrm{B}}-\beta^{*}\right)\right]
$$

A equação (7) é conhecida como decomposição "two-fold", que pode ser expressa como $R=Q+U$, onde o primeiro componente $Q=\left[E\left(X_{A}\right) E\left(X_{B}\right)\right]^{\prime} \beta^{*}$ é a parte do diferencial de renda que é "explicado" pelas diferenças entre grupos nos preditores (efeito quantidade) e o segundo componente $\mathrm{U}=\left[\mathrm{E}\left(\mathrm{X}_{\mathrm{A}}\right)^{\prime}\left(\beta_{\mathrm{A}}-\beta^{*}\right)+\mathrm{E}\left(\mathrm{X}_{\mathrm{B}}\right)^{\text {' }}\right.$ $\left(\beta_{\mathrm{B}}-\beta^{*}\right)$ ] é a parte "não explicada". Esta última é usualmente atribuída à discriminação, mas é importante reconhecer que ela também captura todos os efeitos potenciais de diferenças em variáveis não observadas. 
A parte "não explicada" em (7) permite ampliar a sua decomposição. Deixando $\beta_{\mathrm{A}}=\beta^{*}+\delta_{\mathrm{A}}$ e $\beta_{\mathrm{B}}=\beta^{*}+\delta_{\mathrm{B}}$ com $\delta_{\mathrm{A}}$ e $\delta_{\mathrm{B}}$ como vetores de parâmetros de discriminação entre grupos específicos (discriminação positiva ou negativa, dependendo do sinal), U pode ser expresso como:

$$
\mathrm{U}=\left[\mathrm{E}\left(\mathrm{X}_{\mathrm{A}}\right)^{\prime} \delta_{\mathrm{A}}-\mathrm{E}\left(\mathrm{X}_{\mathrm{B}}\right)^{\prime} \delta_{\mathrm{B}}\right]
$$

Isto é, o componente não explicado do diferencial pode ser dividido em uma parte $\mathrm{U}_{\mathrm{A}}=\mathrm{E}\left(\mathrm{X}_{\mathrm{A}}\right)^{\prime} \delta_{\mathrm{A}}$, a qual mede a discriminação em favor do grupo A, e uma parte $\mathrm{U}_{\mathrm{B}}=\mathrm{E}\left(\mathrm{X}_{\mathrm{B}}\right)^{\prime} \delta_{\mathrm{B}}$, que quantifica a discriminação contra o grupo B. Entretanto, essa interpretação depende da suposição de que não existem preditores relevantes não observados.

A determinação dos componentes da decomposição two-fold é mais complexa porque uma estimativa para o vetor de coeficientes não discriminatórios desconhecidos $\beta^{*}$ é necessária. Por exemplo, pode haver razões para assumir que a discriminação é direcionada para um dos grupos apenas, de modo que $\beta^{*}=\beta_{A}$ ou $\beta^{*}=\beta_{B}$. Assumindo que o grupo A representa os homens e o grupo B as mulheres, se, por exemplo, a discriminação de salário é apenas direcionada contra as mulheres e não existe discriminação (positiva) para homens, deverá ser utilizado $\hat{\beta}_{\mathrm{A}}$ como uma estimativa para $\beta^{*}$ e computar a decomposição (7) como:

$$
\hat{R}=\left(\bar{X}_{A}-\bar{X}_{B}\right)^{\prime} \hat{\beta}_{A}+\bar{X}_{B}^{\prime}\left(\hat{\beta}_{A}-\hat{\beta}_{B}\right)
$$

Similarmente, se não existe discriminação de mulheres, mas apenas (positiva) discriminação de homens, a decomposição será dada por:

$$
\hat{R}=\left(\bar{X}_{A}-\bar{X}_{B}\right)^{\prime} \hat{\beta}_{A}+\bar{X}_{B}^{\prime}\left(\hat{\beta}_{A}-\hat{\beta}_{B}\right)
$$

\section{Análise Descritiva dos Dados}

Nesta seção, será apresentada a análise descritiva dos dados referentes aos principais municípios das sete mesorregiões em que está dividido o estado do Rio Grande do Sul. Cabe destacar que esses municípios foram selecionados de acordo com suas representatividades econômicas e demográficas em suas regiões. Dessa forma, a mesorregião Noroeste Rio-Grandense é representada pelo município de Passo Fundo; a Nordeste Rio-Grandense pelo município de Caxias do Sul; a mesorregião Centro-Ocidental Rio-Grandense pelo município de Santa Maria; a Centro Oriental Rio-Grandense por Santa Cruz do Sul; a Metropolitana de Porto Alegre por Porto Alegre; a Sudoeste Rio-Grandense por Pelotas e a Sudoeste Rio-Grandense pelo município de Bagé. 
Para a realização deste estudo, a base de dados do Censo 2010 foi desagregada, contendo apenas os microdados de cada município. As variáveis utilizadas são as seguintes: rendimento obtido através do trabalho principal, horas trabalhadas por semana, sexo do indivíduo, raça (cor) do indivíduo, indivíduos que estão em idade para ocupar vaga no mercado de trabalho, indivíduos que residem na zona urbana, indivíduos que ocupam posição de referência no domicílio, anos de escolaridade e grau de escolaridade concluído, e se o indivíduo recebe aposentadoria, alguma bolsa de auxílio (bolsa família, por exemplo), ou outra fonte de renda que não seja o rendimento obtido do trabalho principal. A partir dessas informações, são construídas as variáveis utilizadas mais adiante nos modelos econométricos.

A Tabela 1 mostra o rendimento médio (hora) de homens e mulheres nos municípios do Rio Grande do Sul. Essa variável é elaborada a partir da divisão do rendimento obtido por meio do trabalho principal por 4,2 (com base em um mês de 30 dias divididos pelos sete dias da semana) e depois pela variável que representa as horas trabalhadas por semana.

Tabela 1 - Rendimento médio (hora) de homens e mulheres nos municípios do Rio Grande do Sul

\begin{tabular}{cccc}
\hline Municípios & $\begin{array}{c}\text { Rendimento } \\
\text { médio do } \\
\text { homem }\end{array}$ & $\begin{array}{c}\text { Rendimento } \\
\text { médio da } \\
\text { mulher }\end{array}$ & $\begin{array}{c}\text { Razão de } \\
\text { rendimentos } \\
\text { Mulher/Homem }\end{array}$ \\
\hline Bio Grande do Sul & $\mathbf{8 , 1 7}$ & $\mathbf{6 , 9 6}$ & $\mathbf{0 , 8 5}$ \\
\hline Bagé & 7,54 & 7,14 & 0,95 \\
Caxias do Sul & 10,75 & 8,47 & 0,79 \\
Passo Fundo & 8,91 & 8,06 & 0,90 \\
Pelotas & 8,16 & 7,12 & 0,87 \\
Porto Alegre & 13,54 & 12,03 & 0,89 \\
Santa Cruz do Sul & 8,53 & 6,65 & 0,78 \\
Santa Maria & 10,46 & 8,53 & 0,82 \\
\hline
\end{tabular}

Fonte: Elaboração própria a partir de dados do Censo 2010 (IBGE, 2012a).

Como se observa, em todos os municípios os homens recebem um rendimento médio maior que o das mulheres. No Rio Grande do Sul, em média, este diferencial é de 17,4\% em favor dos homens. Stein, Sulzbach e Bartels (2015), utilizando dados da PNAD de 2013, mostram uma diferença ainda maior (20,8\%), sinalizando uma possível tendência de crescimento desse hiato. Em Caxias do Sul e Santa Cruz do Sul, por exemplo, tal hiato em favor dos homens é de $26,9 \%$ e $28,3 \%$, respectivamente, bem acima do que o constatado para o estado como um todo. No entanto, em Bagé esse diferencial é de apenas 5,6\%, significando uma diferença, em princípio, pouco expressiva na média dos rendimentos/hora, 
comparando-se com a dos outros municípios analisados. Uma possível explicação para esse hiato seria a existência de atributos distintos entre os sexos, tais como educação e experiência. Nesse estudo, são utilizadas duas variáveis para captar o capital humano acumulado pelos indivíduos. Inicialmente se trabalha com os anos de estudos completos. Mais adiante, na equação de rendimentos, trabalha-se com a escolaridade por níveis de ensino como forma de captar não linearidades nos retornos da educação. Por sua vez, a variável experiência é definida pela expressão proposta por Mincer (1974) como sendo igual à idade em anos completos subtraída pelos anos de estudos completos menos seis, pois se presume que o indivíduo começa a frequentar a escola a partir dos seus seis anos de idade.

Como se pode observar na Tabela 2, em 2010 as mulheres possuíam 9,3\% a mais de anos de escolaridade que os homens. Stein, Sulzbach e Bartels (2015) mostram que, em 2013, esse percentual aumentou para 16,7\%. Em todos os municípios, as mulheres possuem mais anos de estudos que os homens, chegando essa diferença a mais de um ano de estudo (em média) que os homens. Por exemplo, em Bagé e Pelotas, as mulheres estudam 1,38 e 1,15 ano a mais que os homens, respectivamente. Já em Porto Alegre essa média diminui para 0,7 e em Santa Cruz do Sul, para 0,56 , ambas sendo menores que a diferença média registrada no Rio Grande do Sul.

Tabela 2 - Nível médio de anos de escolaridade e de experiência no mercado de trabalho de homens e mulheres nos municípios do Rio Grande do Sul

\begin{tabular}{ccccc}
\hline \multirow{2}{*}{ Municípios } & \multicolumn{2}{c}{ Anos de estudos } & \multicolumn{2}{c}{ Experiência } \\
\cline { 2 - 5 } Rio Grande do Sul & Homens & Mulheres & Homens & Mulheres \\
\hline Bagé & 9,15 & $\mathbf{9 , 7}$ & $\mathbf{2 2 , 8 4}$ & $\mathbf{2 2 , 3 9}$ \\
Caxias do Sul & 9,64 & 10,53 & 22,86 & 22,4 \\
Passo Fundo & 9,78 & 10,58 & 21,21 & 21,25 \\
Pelotas & 9,09 & 10,24 & 23,18 & 22,01 \\
Porto Alegre & 10,85 & 11,55 & 21,13 & 21,11 \\
Santa Cruz do Sul & 9,4 & 9,96 & 22,6 & 22,06 \\
Santa Maria & 10,05 & 10,97 & 21,43 & 21,39 \\
\hline
\end{tabular}

Fonte: Elaboração própria a partir de dados do Censo 2010 (IBGE, 2012a).

Importante destacar que, em todos os municípios analisados, os níveis médios de anos de escolaridade, tanto para homens quanto para mulheres, são maiores que a média constatada para o estado como um todo. Lucas (1988) discute o papel de municípios na transferência de conhecimento. O autor argumenta que o investimento em Capital Humano gera pelo menos dois resultados. Em primeiro lugar, aumenta a produtividade do próprio trabalhador e, em segundo lugar, 
o resultado mais importante: todos os trabalhadores se beneficiam por trabalhar com colegas mais educados porque estes serão capazes de incrementar a produtividade da empresa e indiretamente das demais empresas da região. Portanto, diferenças de escolaridade média entre municípios podem resultar em diferenças de rendimentos do trabalho na forma de knowledge spillovers (RAUCH, 1991; LUCAS,1988); todavia, esses efeitos externos são mais relevantes em alguns setores do que em outros. Sendo assim, a alocação dos trabalhadores entre os setores também pode ser uma fonte de diferenciais de rendimento do trabalho.

Para elucidar as questões relativas à alocação no mercado de trabalho entre os setores nas sete mesorregiões do Rio Grande do Sul, a Tabela 3 apresenta a proporção de mão-de-obra empregada em cada setor ${ }^{3}$ nos municípios analisados nesse trabalho. A desagregação setorial serve para mostrar o cenário do mercado de trabalho desses municípios, algo que, até então, não há precedente na literatura. Com essas informações, tornam-se mais evidentes as atividades econômicas mais relevantes desses locais, proporcionando a identificação de possíveis efeitos externos nos rendimentos do trabalho que a literatura tradicional baseada em dados agregados por Estado não é capaz de captar.

Tabela 3 - Distribuição da ocupação por setor de atividade econômica nos municípios do Rio Grande do Sul

\begin{tabular}{|c|c|c|c|c|c|c|c|c|}
\hline \multirow[b]{2}{*}{ Setor } & \multicolumn{8}{|c|}{ Frequência percentual } \\
\hline & $\begin{array}{c}\text { Rio } \\
\text { Grande } \\
\text { do Sul }\end{array}$ & Bagé & $\begin{array}{l}\text { Caxias } \\
\text { do Sul }\end{array}$ & $\begin{array}{l}\text { Passo } \\
\text { Fundo }\end{array}$ & $\begin{array}{l}\text { Pelo- } \\
\text { tas }\end{array}$ & $\begin{array}{l}\text { Porto } \\
\text { Alegre }\end{array}$ & $\begin{array}{l}\text { Santa } \\
\text { Cruz } \\
\text { do Sul }\end{array}$ & $\begin{array}{l}\text { Santa } \\
\text { Maria }\end{array}$ \\
\hline Agrícola & $24,59 \%$ & $8,46 \%$ & $3,21 \%$ & $3,01 \%$ & $7,73 \%$ & $0,65 \%$ & $11,54 \%$ & $3,39 \%$ \\
\hline $\begin{array}{l}\text { Indústria da } \\
\text { Transforma- } \\
\text { ção }\end{array}$ & $15,22 \%$ & $7,45 \%$ & $32,01 \%$ & $12,17 \%$ & $6,89 \%$ & $5,99 \%$ & $19,40 \%$ & $7,22 \%$ \\
\hline $\begin{array}{l}\text { Outras ativida- } \\
\text { des industriais }\end{array}$ & $3,10 \%$ & $0,22 \%$ & $0,04 \%$ & $0,17 \%$ & $0,12 \%$ & $0,09 \%$ & $0,07 \%$ & $0,08 \%$ \\
\hline $\begin{array}{l}\text { Indústria da } \\
\text { Construção }\end{array}$ & $6,17 \%$ & $6,58 \%$ & $5,63 \%$ & $7,89 \%$ & $7,53 \%$ & $6,02 \%$ & $6,63 \%$ & $7,41 \%$ \\
\hline $\begin{array}{l}\text { Comércio de } \\
\text { mercadorias }\end{array}$ & $14,77 \%$ & $18,10 \%$ & $16,21 \%$ & $22,34 \%$ & $20,79 \%$ & $17,52 \%$ & $17,63 \%$ & $20,38 \%$ \\
\hline $\begin{array}{l}\text { Prestação de } \\
\text { serviços }\end{array}$ & $2,02 \%$ & $2,36 \%$ & $2,21 \%$ & $2,68 \%$ & $3,18 \%$ & $3,47 \%$ & $2,43 \%$ & $3,68 \%$ \\
\hline $\begin{array}{l}\text { Transporte e } \\
\text { comunicação }\end{array}$ & $4,62 \%$ & $4,78 \%$ & $5,77 \%$ & $5,70 \%$ & $6,60 \%$ & $8,01 \%$ & $4,96 \%$ & $5,55 \%$ \\
\hline $\begin{array}{l}\text { Administração } \\
\text { Pública }\end{array}$ & $5,09 \%$ & $8,72 \%$ & $2,54 \%$ & $4,11 \%$ & $5,10 \%$ & $6,43 \%$ & $4,80 \%$ & $8,94 \%$ \\
\hline
\end{tabular}

3 Para esta análise, utilizou-se como referência a Classificação Nacional de Atividades Econômicas (CNAE), a qual está contida na base de dados do Censo 2010. 
conclusão.

\begin{tabular}{lcccccccc}
\hline \multicolumn{1}{c}{ Setor } & $\begin{array}{l}\text { Rio } \\
\text { Grande } \\
\text { do Sul }\end{array}$ & Bagé & $\begin{array}{c}\text { Caxias } \\
\text { do Sul }\end{array}$ & $\begin{array}{c}\text { Passo } \\
\text { Fundo }\end{array}$ & $\begin{array}{c}\text { Pelo- } \\
\text { tas }\end{array}$ & $\begin{array}{c}\text { Porto } \\
\text { Alegre }\end{array}$ & $\begin{array}{c}\text { Santa } \\
\text { Cruz } \\
\text { do Sul }\end{array}$ & $\begin{array}{c}\text { Santa } \\
\text { Maria }\end{array}$ \\
\hline $\begin{array}{l}\text { Educação } \\
\text { Social }\end{array}$ & $\mathbf{4 , 6 1 \%}$ & $7,32 \%$ & $4,38 \%$ & $6,02 \%$ & $7,93 \%$ & $7,07 \%$ & $6,35 \%$ & $9,00 \%$ \\
$\begin{array}{l}\text { Serviços do- } \\
\text { mésticos }\end{array}$ & $\mathbf{3 , 0 0 \%}$ & $4,11 \%$ & $4,19 \%$ & $7,61 \%$ & $5,32 \%$ & $8,19 \%$ & $4,21 \%$ & $5,65 \%$ \\
$\begin{array}{l}\text { Outras ativi- } \\
\text { dades }\end{array}$ & $\mathbf{5 , 7 0 \%}$ & $10,37 \%$ & $3,96 \%$ & $6,35 \%$ & $8,23 \%$ & $5,33 \%$ & $4,96 \%$ & $9,12 \%$ \\
\hline
\end{tabular}

Fonte: Elaboração própria a partir de dados do Censo 2010 (IBGE, 2012a).

Observa-se que a importância do setor agrícola do estado não é refletida nos municípios analisados, isso porque esses são os centros de suas regiões, apresentando população mais urbana e concentração dos empregos no setor de serviços. Uma exceção na amostra é o município de Caxias do Sul, que apresenta um terço de seus empregos na indústria. O município possui uma aglomeração de atividades ligadas ao setor metal mecânico. Isso pode ser uma fonte de externalidades que incrementam os rendimentos do trabalho nesse setor ${ }^{4}$ em tal município.

Entretanto, para fazer este tipo de inferência, a análise descritiva é insuficiente, pois não faz os devidos controles e não permite uma análise contrafactual. A próxima seção faz isso, a partir da decomposição dos diferenciais de rendimentos entre gêneros, com o objetivo de verificar se esses diferenciais ocorrem por diferenças de características produtivas ou por discriminação. Além disso, caso se confirme a discriminação, a inclusão de um controle por setores de cada município possibilita identificar se a existência de discriminação salarial entre os gêneros é causada por questões de alocação ou se a discriminação intrassetorial tem maior peso neste hiato.

\section{Resultados}

A estimação da equação de rendimentos do tipo minceriana para os municípios do Rio Grande do Sul será realizada, nesta seção, com o objetivo de averiguar os determinantes dos rendimentos nos municípios do estado. O objetivo desse estudo é o de traçar paralelos, com a finalidade de elucidar as peculiaridades do mercado de trabalho de cada região. No entanto, algumas adequações se fizeram necessárias para que as estimações apresentassem a mesma robustez para todos os municípios. Dessa forma, para que as estimativas da variável cor (raça) fossem

$4 \quad$ A Tabela 7 do Apêndice apresenta os rendimentos médios por setor nos municípios analisados. 
significativas, optou-se por trocar a cor de referência de amarela para branca nos municípios de Passo Fundo, Pelotas, Porto Alegre e Santa Maria. Tal alteração se fez necessária pelo fato de que a cor amarela (a qual foi referência na estimação para o Rio Grande Sul) não ter sido significativa para os municípios citados, devido a sua baixa incidência. Além disso, nas estimações - tanto da equação de seleção (Tabela 8 do Apêndice) quanto da equação minceriana para o município de Porto Alegre - omitiu-se a variável que avalia se o indivíduo reside ou não na zona urbana, porque, por se tratar da capital do estado e pelo fato de sua população residir em área urbana, não há sentido de avaliá-la.

Importante destacar que as estimativas dos coeficientes da variável lambda foram, estatisticamente, significativas em todos os municípios analisados, comprovando que a utilização do Modelo de Heckman ${ }^{5}$ é, de fato, essencial para a correção do viés de seleção amostral nesse caso. No entanto, é necessário analisar o porquê da oscilação do sinal do coeficiente da variável lambda na estimação para os municípios. Conforme afirmam Psacharopoulos e Tzannatos (1992), não existe um sinal correto para essa variável, sendo relevante apenas seu nível de significância. O sinal do coeficiente indicará apenas a direção da relação entre essa variável e os rendimentos: um sinal positivo indica que os fatores não observados, os quais induzem o indivíduo a trabalhar, são também diretamente relacionados à sua remuneração. Um sinal negativo sinaliza que esses fatores estão inversamente relacionados aos rendimentos. A Tabela 4 apresenta os resultados da estimação da equação de rendimentos para os municípios analisados nesse trabalho.

5 Os resultados da equação de seleção encontram-se na Tabela 8 do Apêndice. 


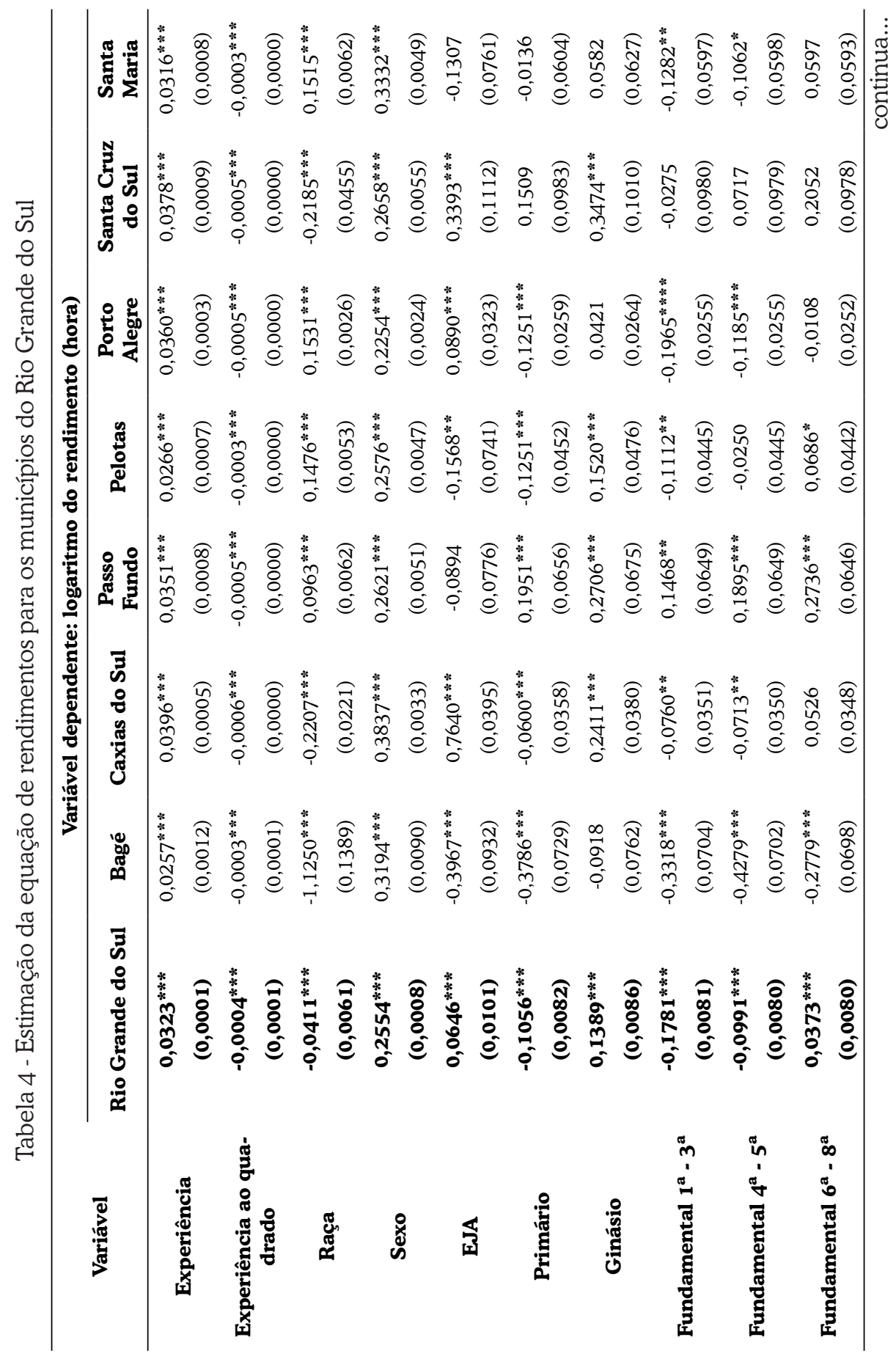




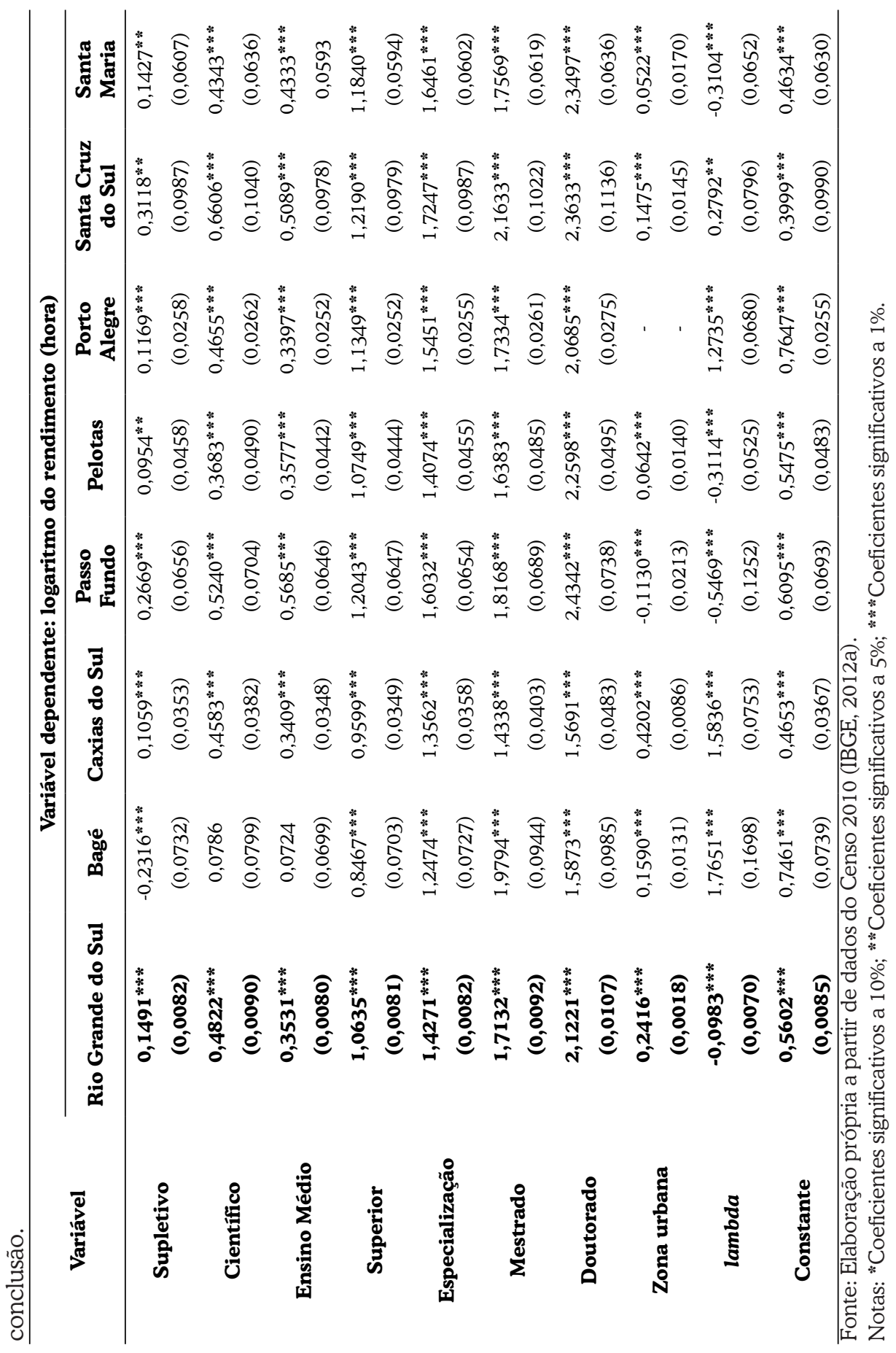


Conforme o esperado, a variável experiência apresentou coeficientes positivos, mostrando que a experiência colabora positivamente com os salários dos indivíduos do Rio Grande do Sul. Da mesma forma, o sinal negativo do coeficiente da variável experiência ao quadrado confirma as taxas decrescentes de retorno. Assim, em todos os municípios analisados, ratifica-se o formato de "U" invertido da relação entre experiência e rendimentos.

No que diz respeito ao gênero (sexo), em todos os municípios analisados, ser do sexo masculino alavanca entre $25 \%$ e $38 \%$ os rendimentos desses indivíduos. Tal constatação sinaliza, da mesma forma que foi observado para o estado como um todo, que a discriminação nos mercados de trabalho de tais municípios é uma possível realidade.

Em todos os municípios avaliados, o "efeito diploma" é refletido em ganhos cada vez maiores, confirmando que a conclusão de ciclos estudantis favorece a prosperidade financeira dos indivíduos. Importante ressaltar que os níveis mais elevados de educação, em todos os municípios, foram significativos, ratificando sua importância na determinação dos rendimentos.

O prêmio pela conclusão do ensino superior (graduação) é bem semelhante em todos os municípios. Em Bagé, a conclusão do ensino médio mostrou não causar nenhum efeito nos rendimentos. A obtenção do título de nível superior, no entanto, gera um retorno de $77,43 \%$ nos rendimentos dos indivíduos, ou seja, as possibilidades de ganhos maiores em Bagé só ocorrem quando se obtém a graduação. Em Caxias, a conclusão do nível superior impulsiona em 61,9\% os rendimentos dos trabalhadores. O forte setor industrial desse município fornece postos de emprego para todos os níveis de educação. Dessa forma, seus trabalhadores procuram níveis maiores de qualificação, pois sabem que isso pode refletir em maiores ganhos financeiros. Nos outros municípios (com exceção de Passo Fundo), este "efeito diploma" gera retornos maiores que os registrados para o Rio Grande do Sul. Destaque para Porto Alegre e Santa Maria, onde tais retornos são de 79,52\% e $75,07 \%$, respectivamente.

Mesmo sendo polos educacionais e, com isso, tendo uma oferta elevada de mão de obra qualificada, essa qualificação mostra-se bastante valorizada pelo mercado de trabalho desses locais. Em Bagé e Santa Cruz do Sul, o título de Mestre gera retornos bem acima do registrado nos outros municípios (113,27\% e 94,43\%, respectivamente). Em municípios como Passo Fundo, Pelotas e Santa Maria, os prêmios pela titulação de Doutor retornam em 122,99\%, 118,49\% e 116,57\%, respectivamente, nos rendimentos dos trabalhadores. Nesse caso, mais uma vez, entra em questão o fato de tais locais possuírem universidades e necessitarem, por isso, de profissionais com esse nível de qualificação para preencherem seus quadros funcionais, dado que em universidades públicas exige-se esse título para que se exerça a função de docência. 
Os retornos analisados por residir na zona urbana apresentaram comportamento de acordo com o esperado - positivos - em todos os municípios, exceto em Passo Fundo, onde o coeficiente desta variável foi negativo. Dessa forma, conclui-se que morar na zona rural não influencia negativamente nos retornos aos rendimentos dos residentes deste município.

A decomposição do diferencial de rendimentos entre homens e mulheres nos municípios do Rio Grande do Sul através do procedimento de Oaxaca-Blinder é mostrada na Tabela 5. Em todos eles, os homens ganham, em média, maiores salários que as mulheres. Além disso, esse diferencial apresenta-se bem homogêneo; no entanto, os componentes que explicam o diferencial de rendimentos (atributos produtivos) e os que não explicam (discriminatório) apresentam resultados diferenciados.

Tabela 5 - Hiato de rendimentos, componente explicado e componente não explicado estimados para os municípios do Rio Grande do Sul com e sem controle para atividade econômica

\begin{tabular}{|c|c|c|c|c|c|}
\hline \multirow[b]{2}{*}{ Municipios } & \multirow{2}{*}{$\begin{array}{l}\text { Hiato } \\
\text { de Ren- } \\
\text { dimen- } \\
\text { tos }\end{array}$} & \multicolumn{2}{|c|}{ Sem controle } & \multicolumn{2}{|c|}{ Com controle } \\
\hline & & $\begin{array}{c}\text { Compo- } \\
\text { nente Ex- } \\
\text { plicado }\end{array}$ & $\begin{array}{c}\text { Compo- } \\
\text { nente Não } \\
\text { Explicado }\end{array}$ & $\begin{array}{c}\text { Compo- } \\
\text { nente Ex- } \\
\text { plicado }\end{array}$ & $\begin{array}{c}\text { Compo- } \\
\text { nente Não } \\
\text { Explicado }\end{array}$ \\
\hline \multirow{2}{*}{$\begin{array}{l}\text { Rio Gran- } \\
\text { de do Sul }\end{array}$} & 0,1448 & $-0,0534$ & 0,1982 & $-0,0309$ & 0,1756 \\
\hline & $(0,0022)$ & $(0,0014)$ & $(0,0022)$ & $(0,0032)$ & $(0,0036)$ \\
\hline \multirow{2}{*}{ Bagé } & 0,0915 & $-0,2175$ & 0,3090 & $-0,0651$ & 0,1567 \\
\hline & $(0,0270)$ & $(0,0232)$ & $(0,0300)$ & $(0,0413)$ & $(0,0450)$ \\
\hline \multirow{2}{*}{$\begin{array}{l}\text { Caxias do } \\
\text { Sul }\end{array}$} & 0,2701 & $-0,0774$ & 0,3475 & $-0,0939$ & 0,3641 \\
\hline & $(0,0109)$ & $(0,0082)$ & $(0,0114)$ & $(0,0133)$ & $(0,0154)$ \\
\hline \multirow{2}{*}{$\begin{array}{l}\text { Passo Fun- } \\
\text { do }\end{array}$} & 0,1712 & $-0,0920$ & 0,2632 & $-0,0958$ & 0,2670 \\
\hline & $(0,0174)$ & $(0,0112)$ & $(0,0161)$ & $(0,0265)$ & $(0,0288)$ \\
\hline \multirow{2}{*}{ Pelotas } & 0,1270 & $-0,1326$ & 0,2596 & $-0,0664$ & 0,1934 \\
\hline & $(0,0158)$ & $(0,0104)$ & $(0,0148)$ & $(0,0247)$ & $(0,0268)$ \\
\hline \multirow{2}{*}{ Porto Alegre } & 0,0940 & $-0,1449$ & 0,2390 & $-0,1016$ & 0,1956 \\
\hline & $(0,0114)$ & $(0,0096)$ & $(0,0115)$ & $(0,0129)$ & $(0,0144)$ \\
\hline \multirow{2}{*}{ Santa Cruz } & 0,1979 & $-0,0558$ & 0,2537 & $-0,0846$ & 0,2825 \\
\hline & $(0,0204)$ & $(0,0121)$ & $(0,0174)$ & $(0,0298)$ & $(0,0322)$ \\
\hline \multirow{2}{*}{ Santa Maria } & 0,1839 & $-0,1230$ & 0,3069 & $-0,0386$ & 0,2225 \\
\hline & $(0,0179)$ & $(0,0113)$ & $(0,0156)$ & $(0,0303)$ & $(0,0320)$ \\
\hline
\end{tabular}

Fonte: Elaboração própria a partir de dados do Censo 2010 (IBGE, 2012a). Nota: Todos os coeficientes foram significativos a $1 \%$. 
No Rio Grande do Sul, o diferencial dos logaritmos é de 0,1448, ou seja, isso pode ser interpretado como uma diferença de rendimentos de $14,48 \%$ em favor dos homens. Com dados da PNAD de 2013, Stein, Sulzbach e Bartels (2015) constataram esse mesmo diferencial em torno de $20 \%$, ou seja, um aumento significativo em relação a 2010. Dentre os municípios, destaque para Caxias, que apresentou um diferencial de $27,01 \%$ em favor dos homens.

Em todos os municípios analisados, os coeficientes do componente explicativo da decomposição apresentaram sinais negativos. Dessa forma, constata-se que esse diferencial de rendimentos entre homens e mulheres não é explicado pelos atributos produtivos desses indivíduos, ou seja, as diferenças de níveis de escolaridade e de experiência não explicam o diferencial de rendimentos entre os gêneros nos locais estudados. Assim, embora as mulheres possuam mais anos de estudo e nível experiência semelhante ao dos homens (resultados verificados em todos os municípios), esses atributos não são valorizados, nas mulheres, da mesma forma que são valorizados nos homens.

Entretanto, o componente não explicado mostrou sinal positivo para todos os municípios. Isso significa que existe a possibilidade de um processo de discriminação em favor dos homens nos mercados de trabalho de todos os municípios analisados. Assim, o sinal positivo do componente não explicado ou discriminatório indica que, mesmo as mulheres possuindo maiores atributos produtivos do que os homens, esses são valorizados em maior magnitude nos homens, isto é, fazendo com que a discriminação se sobreponha às habilidades dos indivíduos. Porém, é importante que se ressalte que este hiato de rendimentos em favor dos homens pode ser gerado pela inserção dos homens em setores da economia que remuneram em patamares mais elevados do que aqueles que empregam maiores percentuais de mulheres.

Para verificar essa suposição, estimaram-se duas decomposições a fim de analisar a discriminação entre os setores e intrassetores: uma sem controlar as atividades econômicas apresentadas; outra, controlando as mesmas. O objetivo dessa estratégia é verificar, no primeiro caso, a magnitude da discriminação entre os gêneros na amostra como um todo, buscando evidenciar uma possível discriminação alocativa, ou seja, empregos que são ocupados majoritariamente por um dos gêneros. Batista e Cacciamali (2009) alertam para a possibilidade de segmentação de mercado nesse tipo de situação, pois, embora os indivíduos sejam igualmente qualificados, as ocupações não são acessíveis igualmente para ambos os grupos. Isso se torna crível a partir da constatação (Tabela 3) de que, dos doze setores analisados, oito são ocupados em sua maioria por homens. No segundo caso, busca-se realizar esta análise contrafactual dentro de cada atividade econômica analisada. Assim, é possível identificar a discriminação por gênero intrassetor em cada município. 
Os resultados mostram que o controle para atividades econômicas diminuiu a magnitude do componente não explicado (discriminatório) no Rio Grande do Sul (-12,87\%) em alguns municípios. Em Bagé, esse valor diminuiu em 97,17\%. Já em Pelotas, essa diferença negativa foi de 34,22\%; em Santa Maria, 37,93\%; e em Porto Alegre, 22,19\%. Esses resultados mostram que a discriminação alocativa tem um peso relativamente grande no momento em que se contrata um trabalhador nesses municípios, principalmente em Bagé. Isso significa que, em uma escolha entre um homem e uma mulher, a preferência pelo indivíduo do sexo masculino é maior.

Além dessa possibilidade, a discriminação alocativa pode ser também uma consequência do desejo do homem em manter seu status ocupacional, ou até mesmo seu prestígio (GOLDIN, 2002). Isto é, pode-se atribuir ao homem um desejo de distância das mulheres para proteger seu status como membros de um grupo profissional. Os homens podem ser hostis para aceitarem a entrada, em sua ocupação, de mulheres, mesmo que elas atendam às qualificações necessárias para assumir tal ocupação. Por sua vez, O’Neill e O’Neill (2005) acreditam que as diferenças salariais entre homens e mulheres residam na ideia da "não comodidade”, uma vez que, provavelmente, a exposição a riscos requeira prêmios. Assim, os empregos que apresentam este tipo de situação são ocupados por homens, pois homens e mulheres diferem de atitudes. De acordo com os autores, os homens possuem maior responsabilidade de fornecer recursos financeiros à família; consequentemente, trabalham mais, mais continuamente, além de se submeterem a empregos de difícil execução.

Outros motivos também são relevantes para explicar esse tipo de discriminação como, por exemplo, as desigualdades decorrentes da natureza dos próprios empregos. Ocupações e firmas individuais diferem na medida em que oferecem horários de trabalho flexíveis e ambiente de trabalho menos estressantes, os quais são mais suscetíveis de serem valorizados por mulheres. Sendo assim, essas e outras comodidades tornam-se um preço a essas mulheres, podendo acarretar baixos salários (O’NEILL; O’NEILL, 2005). Adicionalmente, Goldin (2002) ressalta que regras sindicais e políticas de empresas têm sido usadas para restringir a entrada de mulheres. Dessa forma, a inserção de mulheres em postos de trabalho que exijam força "braçal" - "músculo" em vez de "cérebro" - acaba sendo restringida por essas questões institucionais. Além disso, Kuhn e Shen (2009) explicam que as restrições discriminatórias são altamente trabalho-específicas, com a mesma firma impondo especificidades em alguns trabalhos detalhados (com relação a gênero, cor e aparência física, por exemplo), porém, por outro lado, abrem mão de tais especificidades em outros tipos de trabalhos. Assim, nas mesmas empresas existem funções puramente masculinas, outras puramente femininas e outras que podem ser desempenhadas por ambos os sexos. 
Batista e Cacciamali (2009) alertam que a migração de trabalhadores mais qualificados para os mercados locais com essas características é um fator relevante para a discriminação, pela possibilidade de existir segmentação em tais mercados. Dependendo dessas características, pode haver o favorecimento de um grupo em detrimento de outro.

Por outro lado, com a inclusão do controle para os setores, observou-se em Caxias do Sul e Santa Cruz do Sul um aumento do componente discriminatório em $4,56 \%$ e 10,19\%, respectivamente. Em Passo Fundo, houve também um aumento desse componente, porém mais modesto, de 1,42\%. Nesses casos, a discriminação intrassetor mostrou uma influência maior que a discriminação alocativa, isto é, a discriminação constatada dentro de cada atividade econômica é maior que a verificada no mercado de trabalho como um todo nesses municípios.

A Tabela 6 apresenta a decomposição de Oaxaca-Blinder detalhada para as médias. Os resultados mostram que, se as mulheres fossem remuneradas pela sua escolaridade, receberiam maiores salários que os homens em todos os municípios analisados. Em Bagé, por exemplo, se somente a escolaridade fosse o determinante dos rendimentos, as mulheres ganhariam $R \$ 1,20$ por hora trabalhada a mais que os homens; em Pelotas, ganhariam $R \$ 1,15$ a mais e, em Santa Maria, $\mathrm{R} \$ 1,14$ a mais. Supondo um emprego de 40 horas semanais, as mulheres ganhariam, em média, $R$ \$201,60 a mais por mês que os homens em Bagé; $R$ \$ 193,20 a mais em Pelotas e R $\$ 191,52$ a mais em Santa Maria, por exemplo. Mesmo com a inclusão do controle para atividades econômicas, as mulheres continuariam recebendo mais que os homens se a sua escolaridade fosse o fator determinante para a definição dos rendimentos nestes municípios; entretanto, esses valores seriam $5 \%$ menores em Bagé, 2,6\% menores em Pelotas e 3,5\% menores em Santa Maria. 
Tabela 6 - Decomposição detalhada de Oaxaca-Blinder para as médias sem controle e com controle para os setores das atividades econômicas

\begin{tabular}{|c|c|c|c|c|c|c|c|c|}
\hline Variável & $\begin{array}{c}\text { Rio } \\
\text { Gran- } \\
\text { de do } \\
\text { Sul }\end{array}$ & Bagé & $\begin{array}{l}\text { Caxias } \\
\text { do Sul }\end{array}$ & $\begin{array}{l}\text { Passo } \\
\text { Fundo }\end{array}$ & Pelotas & $\begin{array}{c}\text { Porto } \\
\text { Alegre }\end{array}$ & $\begin{array}{c}\text { Santa } \\
\text { Cruz } \\
\text { do Sul }\end{array}$ & $\begin{array}{l}\text { Santa } \\
\text { Maria }\end{array}$ \\
\hline \multicolumn{9}{|l|}{$\begin{array}{c}\text { Sem } \\
\text { Controle }\end{array}$} \\
\hline $\begin{array}{l}\text { Escolari- } \\
\text { dade }\end{array}$ & $-0,0988$ & $-0,1836$ & $-0,0633$ & $-0,0862$ & $-0,1414$ & $-0,1010$ & $-0,0644$ & $-0,1280$ \\
\hline $\begin{array}{l}\text { Experiên- } \\
\text { cia }\end{array}$ & 0,0158 & 0,0053 & 0,0039 & 0,0012 & 0,0039 & 0,0026 & 0,0117 & 0,0041 \\
\hline $\begin{array}{c}\text { Experi- } \\
\text { ência ao } \\
\text { quadrado }\end{array}$ & $-0,0035$ & $-0,0025$ & $-0,0026$ & $-0,0006$ & $-0,0008$ & $-0,0017$ & $-0,0011$ & $-0,0008$ \\
\hline Raça & 0,0000 & 0,0020 & 0,0002 & $-0,0033$ & $-0,0021$ & $-0,0026$ & 0,0000 & $-0,0016$ \\
\hline \multicolumn{9}{|l|}{$\begin{array}{c}\text { Com } \\
\text { controle }\end{array}$} \\
\hline $\begin{array}{l}\text { Escolari- } \\
\text { dade }\end{array}$ & $-0,0812$ & $-0,1343$ & $-0,0559$ & $-0,0763$ & $-0,1152$ & $-0,0904$ & $-0,0572$ & $-0,0982$ \\
\hline $\begin{array}{l}\text { Experiên- } \\
\text { cia }\end{array}$ & 0,0150 & 0,0046 & 0,0040 & 0,0010 & 0,0033 & 0,0025 & 0,0100 & 0,0036 \\
\hline $\begin{array}{c}\text { Experi- } \\
\text { ência ao } \\
\text { quadrado }\end{array}$ & $-0,0043$ & $-0,0022$ & $-0,0030$ & $-0,0004$ & $-0,0005$ & $-0,0015$ & $-0,0002$ & $-0,0009$ \\
\hline Raça & 0,0000 & 0,0018 & 0,0002 & $-0,0030$ & $-0,0020$ & $-0,0027$ & 0,0000 & $-0,0013$ \\
\hline
\end{tabular}

Fonte: Elaboração própria a partir de dados do Censo 2010 (IBGE, 2012a).

Nota: Todos os coeficientes foram significativos a $1 \%$.

Por outro lado, se somente a experiência no mercado de trabalho fosse o determinante para a definição dos rendimentos, os homens ganhariam mais que as mulheres em todos os municípios estudados. Mesmo com a inclusão do controle para os setores da economia, os valores dos coeficientes dessa variável não sofreram alterações relevantes. É importante que se diga que a magnitude da diferença isolada gerada pela experiência em favor dos homens é muito pequena quando comparada com a diferença originada pela escolaridade em favor das mulheres. Essa informação reforça ainda mais a hipótese de que existe discriminação no mercado de trabalho do Rio Grande do Sul e dos municípios analisados, tanto entre setores como intrassetorial, ratificando que se os atributos produtivos fossem valorizados, as mulheres receberiam maiores salários que os homens.

Embora os resultados apresentados neste trabalho forneçam evidências suficientes para sustentar a existência de discriminação nos mercados de trabalho 
analisados, algumas questões não são possíveis de serem observadas com os dados e estimações realizadas. Por exemplo, de acordo com Fernandes, Herskovic e Mation (2010), a redução média dos rendimentos das mulheres, que, inicialmente, ocorre após a saída da adolescência e após a conclusão da sua formação educacional, amplia-se quando elas se aproximam da idade culturalmente associada ao matrimônio e à fecundidade. Sendo assim, à medida que a idade das mulheres avança, estaria associada a elas uma probabilidade maior de ocorrência de algum fato importante relacionado à fecundidade, o que teria um impacto negativo em relação à sua produtividade no trabalho.

Nesse contexto, Stein, Sulzbach e Bartels (2015) mostram empiricamente que, no Rio Grande do Sul, a probabilidade de interrupção da carreira profissional é muito maior para o gênero feminino, sendo essa probabilidade de $35,1 \%$ para as mulheres e de 14,7\% para os homens. Os autores destacam ainda que as mulheres têm, em média, uma jornada de trabalho menor que a dos homens, o que acentua o aumento desse diferencial em favor dos homens. Por outro lado, ressaltam que escolaridade da mulher contribui para a redução desse hiato.

O'Neill e O'Neill (2005) destacam que a magnitude gerada por essa questão no diferencial de salários é um desafio, visto que, mesmo que se saiba que o papel da mulher dentro da família afete sua carreira profissional, seria necessária a existência de uma variável na base de dados do Censo que analisasse o tempo de experiência no mercado de trabalho. Embora a utilização do método proposto por Mincer forneça essa análise a esse estudo, ele não permite a mensuração dessa magnitude.

Por outro lado, verifica-se uma possível tendência de queda do diferencial ao longo do tempo, observada através da comparação com outros trabalhos, provavelmente justificada por dois aspectos: primeiro porque as mulheres estão buscando cada vez mais qualificação, e segundo porque este nível mais elevado de qualificação as credencia para ocupar cargos e postos de trabalho que remunerem mais. Segundo Goldin (2002), estudos empíricos nos anos de 1970 e 1980 indicam que o mercado de trabalho tem finalmente respondido e que a discriminação salarial foi mais baixa entre os indivíduos mais altamente qualificados e que essa possível mudança nos padrões de admissão ocorra pelo próprio dinamismo da economia. Entretanto, comparando-se os resultados obtidos nesse trabalho com os obtidos por Stein, Sulzbach e Bartels (2015), é possível observar que no Rio Grande do Sul esse diferencial apresenta uma tendência de aumento. Dessa forma, possivelmente alterações no mercado de trabalho estejam intensificando esse cenário, o que incita novas investigações para que se possam identificar as causas deste aumento.

Goldin (2002) acredita que a criação de setores credenciados-distinção de empregos femininos e masculinos- pode aumentar a integração e diminuir a dis- 
criminação salarial. A criação de ocupações somente femininas tende a diminuir essa discriminação, pois como as mulheres possuem mais qualificação que os homens, tais empregos remunerariam bem mais se comparados com as existentes para ocupações somente masculinas.

\section{Considerações Finais}

O objetivo principal deste artigo foi investigar a existência de indícios de discriminação contra as mulheres nos mercados de trabalho dos municípios do Rio Grande do Sul analisados. Além disso, contribuir com a literatura que estuda os diferenciais de rendimentos por gênero no Rio Grande do Sul por meio da análise do comportamento desses diferenciais no estado.

Ao se estimar a equação de rendimentos do trabalho, ficou comprovada a necessidade de correção para o problema de seletividade amostral. A partir desse método, tornou-se possível identificar que a conclusão de um curso de graduação é essencial para um aumento considerável nos rendimentos dos indivíduos. Destaca-se o procedimento diferenciado utilizado neste artigo, no que diz respeito à identificação dos retornos dos vários níveis de escolaridade a partir de sua desagregação por nível de qualificação. Conforme Cacciamali, Tatei e Rosalino (2009), a utilização apenas dos anos de escolaridade gera um problema de mensuração, pois o último grupo desta variável (15 anos de estudo) compreende todos os indivíduos que completaram o ensino superior juntamente com os que concluíram pós-graduação (Mestrado e Doutorado). Desse modo, tal desagregação evidenciou a aparente contribuição não linear da educação nos rendimentos, evidenciando o fato de que quanto maiores níveis de educação forem alcançados, maiores serão os retornos obtidos, principalmente ao apresentar os elevados retornos dos níveis de pós-graduação nos rendimentos. Por exemplo, na maioria dos municípios analisados, a obtenção do título de Mestre aumentou em mais de $100 \%$ o rendimento dos indivíduos.

Ademais, é importante que se ressalte a colaboração deste estudo para reflexões importantes relativas à educação nos municípios do Rio Grande do Sul. É essencial que se repense a questão da educação básica no estado, visto que os retornos originados pela qualificação no ensino médio são muito pequenos, levando a crer que essa formação pouco está alterando a produtividade dos indivíduos dos municípios analisados.

Com relação à discriminação de rendimentos por gêneros, este trabalho apresentou alguns elementos adicionais com relação ao que se tem na literatura sobre o tema. Primeiramente, a análise por municípios possibilitou controlar, pelo menos, uma fonte de heterogeneidade não observada bastante comum em trabalhos que utilizam informações estaduais. Desse modo, ficou nítida a diferença das 
características do emprego em cada um dos locais estudados, possibilitando a análise do comportamento do diferencial de rendimentos entre os gêneros em cada município, em que se constatou a existência de discriminação contra as mulheres em todos eles. Adicionalmente, com a inclusão dos controles para os setores de atividade econômica, foi possível identificar que a discriminação por gênero ocorre não somente pelas questões alocativas já destacadas na literatura, mas também ocorre dentro dos setores e com um diferencial de rendimentos significativo, algo até então pouco explorado na literatura.

Por fim, é pertinente salientar que, devido à limitação de informações disponíveis, não é possível avaliar os motivos que levam os empregadores a discriminar as mulheres em termos alocativos ou dentro de cada setor. De fato, isso é uma limitação relevante de estudos econométricos a respeito de discriminação, uma vez que esse tema envolve questões relacionadas à cultura, legislação trabalhista e a outros elementos que estão além do que a teoria econômica e os modelos econométricos são capazes de captar.

\section{Referências}

AIGNER, D. J.; CAIN, G. G. Statistical theories of discrimination in labor market. Industrial and Labor Relations View, v. 30, n. 2, p. 175-187, 1977.

ARROW, K. The theory of discrimination. In: REE, A.; ASHENFELTER, O. E. (Ed.). Discrimination in labor markets. Princeton: Princeton University Press, 1973.

BARROS, R. P.; RAMOS, L.; SANTOS, E. Gender differences in Brazilian labor market. In: SCHULTZ, P. Investments in women human capital. Chicago: Chicago Press, 1995.

BATISTA, N. N. F.; CACCIAMALI, C. C. Diferencial de salários entre homens e mulheres segundo a condição de migração. Revista Brasileira de Estudos Populacionais, v. 26, n. 1, p. 97-115, jan./jun. 2009.

BECKER, G. The economics of discrimination. Chicago: The University of Chicago Press, 1957.

BLINDER, A.S. Wage discrimination: reduced form and structural estimates. Journal of Human Resources 8 (4), 436-455, 1973.

CACCIAMALI, C. C.; TATEI, F.; ROSALINO, J. W. Estreitamento dos diferenciais de salário e aumento do grau de discriminação: limitações da mensuração padrão? Planejamento $e$ Políticas Públicas, n. 33, jul./dez. 2009.

CAMARGO, J. M.; SERRANO, F. Os dois mercados: homens e mulheres na indústria brasileira. Rio de Janeiro: PUC-Rio, 1983. (Texto para discussão, n. 46).

CAMBOTA, J. N.; MARINHO, E. L. L. Discriminação como uma das fontes de desigualdade de rendimentos no mercado de trabalho das regiões nordeste e sudeste. EconomiA, Brasília, DF, v. 7, n. 3, p. 597-619, 2007. 
CAMERON, A. C.; TRIVEDI, P. K. Microeconometrics: methods and applications. New York: Cambridge University Press, 2005.

CAVALIERI, C. H.; FERNANDES, R. Diferenciais de salário por gênero e cor: uma comparação entre as regiões metropolitanas Brasileiras. Revista de Economia Política, v. 18, n. 1, p. 158-175, 1998.

CIRINO, J. F.; LIMA, J. E. Diferenças de rendimento entre as regiões metropolitanas de Belo Horizonte e Salvador: uma discussão a partir da decomposição de Oaxaca-Blinder. In: CONGRESSO DA SOCIEDADE BRASILEIRA DE ECONOMIA, ADMINISTRAÇÃO E SOCIOLOGIA RURAL, 48., 2010, Campo Grande. Anais... Campo Grande: SOBER, 2010.

FERNANDES, M. M.; HERSKOVIC, B.; MATION, L. F. Diferenciais salariais ao longo do ciclo da vida. In: ENCONTRO NACIONAL DE ECONOMIA, 37., 2009, Foz do Iguaçu. Anais... Foz do Iguaçu: ANPEC, 2009.

GIUBERTI, A. C.; MENEZES-FILHO, N. Discriminação de rendimentos por gênero: uma comparação entre o Brasil e os Estados Unidos. Economia Aplicada, v. 93, n. 3, p. 369-383, 2005 .

GOLDIN, C. A pollution theory of discrimination: male and female differences in occupations and earnings. Cambridge: National Bureau of Economic Research, 2002. (Working paper, n. 8985).

GORDON, I. R.; MCCANN, P. Industrial clusters: complexes, agglomeration and/or social networks. Urban Studies, v. 37, n. 3, p.513-532, 2000.

HECKMAN, J. J. Sample Selection bias as a specification error. Econometrica, v. 47, n. 1, p. 153-162, 1979.

IBGE. Censo Demográfico 2010. Disponível em: <http:/www.ibge.gov.br/home/estatistica/ populacao/censo2010/resultados_gerais_amostra/resultados_gerais_amostra_tab_uf_ microdados.shtm $\geq$. Acesso em: 01 set. $201 \overline{2}$ a.

. Pesquisa Nacional por Amostra de Domicílios. Disponível em: <http://www.ibge.gov. $\mathrm{br} /$ home/estatistica/pesquisas/pesquisa_resultados.php?id_pesquisa $=40>$. Acesso em: 01 set. $2012 b$.

JACINTO, P. A. Diferenciais de salários por gênero na Indústria avícola da região sul do Brasil: uma análise com micro dados. Revista de Economia e Sociologia Rural, Brasília, DF, v. 43, n. 3, p. 529-555, 2005.

JANN, B. A stata implementation of the Blinder-Oaxaca decomposition. The Stata Journal, v. 8 , n. 4, p. 453-479, 2008.

KUHN, P.; SHEN, K. Employers preferences for gender, age, height, and beauty: direct evidence. Cambridge: National Bureau of Economic Research, 2009. (Working paper, n. 15564).

LEME, M. C.; WAJNMAN, S. Diferenciais de rendimentos por gênero. In: LISBOA, B. L.; MENEZES, A. (Org.). Microeconomia e sociedade no Brasil. São Paulo: Contra Capa/FGV, 2001. 
LOUREIRO, P. R. A. Uma resenha teórica e empírica sobre economia da discriminação. Revista Brasileira de Economia, v. 57, n. 1, p. 125-157, jan./mar. 2003.

LUCAS, R. E. On the mechanics of economic development. Journal of Monetary Economics, v. 22, n. 1, p. 3-42, 1988.

MCCANN, P. Urban and regional economics. Oxford: Oxford University Press, 2001.

MINCER, J. Schooling, experience and earnings. New York: Columbia University Press, 1974.

O'NEILL, J. E.; O'NEILL, D. M. What do wage differentials tell us about labor market discrimination? Research in Labor Economics, v. 24, p. 293-357, 2005.

OAXACA, R. Male-female wage differentials in urban labor markets. International Economic Review, v. 14, n. 3, p. 693-709, 1973.

PHELPS, E. S. The statistical theory of racism and sexism. American Economic Review, v. 62, n. 4, p.659-661, 1972.

PSACHAROPOULOS, G.; TZANNATOS, Z. Women's employment and pay in Latin America: overview and methodology. Washington, DC: The World Bank, 1992.

RAUCH, J. Productivity gains from geographic concentration of human capital: evidence from the cities. Cambridge: National Bureau of Economic Research, 1991. (NBER Working paper, n. 3905).

SCORZAFAVE, L. G.; PAZELLO, E. T. Using normalized equations to solve the indetermination problem in the Oaxaca-Blinder decomposition: an application to the gender wage gap in Brazil. Revista Brasileira de Economia, Rio de Janeiro, v.61, n. 4, p. 535-548, 2007.

STEIN, G.; SULZBACH, V. N.; BARTELS, M. Relatório sobre o mercado de trabalho do Rio Grande do Sul - 2001-13. Porto Alegre: FEE, 2015. 


\section{Apêndice}

Tabela 7 - Rendimento médio (hora) por ramo de atividade nos municípios do Rio Grande do Sul

\begin{tabular}{|c|c|c|c|c|c|c|c|c|}
\hline Setor & $\begin{array}{c}\text { Rio } \\
\text { Grande } \\
\text { do Sul }\end{array}$ & Bagé & $\begin{array}{l}\text { Caxias } \\
\text { do Sul }\end{array}$ & $\begin{array}{l}\text { Passo } \\
\text { Fundo }\end{array}$ & $\begin{array}{l}\text { Pelo- } \\
\text { tas }\end{array}$ & $\begin{array}{l}\text { Porto } \\
\text { Alegre }\end{array}$ & $\begin{array}{c}\text { Santa } \\
\text { Cruz } \\
\text { do } \\
\text { Sul } \\
\end{array}$ & $\begin{array}{l}\text { Santa } \\
\text { Maria }\end{array}$ \\
\hline Agrícola & 4,18 & 6,56 & 5,14 & 7,97 & 5,56 & 9,00 & 5,00 & 8,44 \\
\hline $\begin{array}{l}\text { Indústria } \\
\text { da Trans- } \\
\text { formação }\end{array}$ & 6,25 & 5,40 & 9,17 & 6,77 & 6,26 & 11,66 & 6,68 & 7,44 \\
\hline $\begin{array}{l}\text { Outras } \\
\text { atividades } \\
\text { industriais }\end{array}$ & 6,70 & 14,16 & 11,38 & 5,75 & 12,56 & 20,97 & 4,38 & 13,55 \\
\hline $\begin{array}{l}\text { Indústria } \\
\text { da Cons- } \\
\text { trução }\end{array}$ & 5,92 & 5,00 & 8,99 & 6,50 & 5,30 & 9,07 & 5,66 & 5,75 \\
\hline $\begin{array}{l}\text { Comércio } \\
\text { de merca- } \\
\text { dorias }\end{array}$ & 6,41 & 6,15 & 9,10 & 7,36 & 6,49 & 9,14 & 6,79 & 7,62 \\
\hline $\begin{array}{l}\text { Prestação } \\
\text { de serviços }\end{array}$ & 6,69 & 5,42 & 8,68 & 6,99 & 6,96 & 9,46 & 6,22 & 6,63 \\
\hline $\begin{array}{l}\text { Transporte } \\
\text { e comuni- } \\
\text { cação }\end{array}$ & 8,34 & 6,70 & 9,72 & 8,43 & 7,71 & 11,99 & 7,59 & 8,74 \\
\hline $\begin{array}{l}\text { Adminis- } \\
\text { tração } \\
\text { Pública }\end{array}$ & 11,08 & 11,57 & 16,35 & 14,32 & 13,53 & 22,67 & 12,11 & 17,71 \\
\hline Educação & 10,61 & 11,19 & 13,49 & 12,25 & 13,33 & 17,19 & 10,95 & 15,64 \\
\hline Social & 10,62 & 10,55 & 12,92 & 11,25 & 10,54 & 17,88 & 10,81 & 12,20 \\
\hline $\begin{array}{l}\text { Serviços } \\
\text { domésticos }\end{array}$ & 4,01 & 3,64 & 6,07 & 4,93 & 3,64 & 5,75 & 4,31 & 3,98 \\
\hline $\begin{array}{l}\text { Outras } \\
\text { atividades }\end{array}$ & 8,38 & 8,19 & 10,58 & 9,41 & 8,40 & 13,08 & 9,68 & 9,79 \\
\hline
\end{tabular}

Fonte: Elaboração própria a partir de dados do Censo 2010 (IBGE, 2012a). 


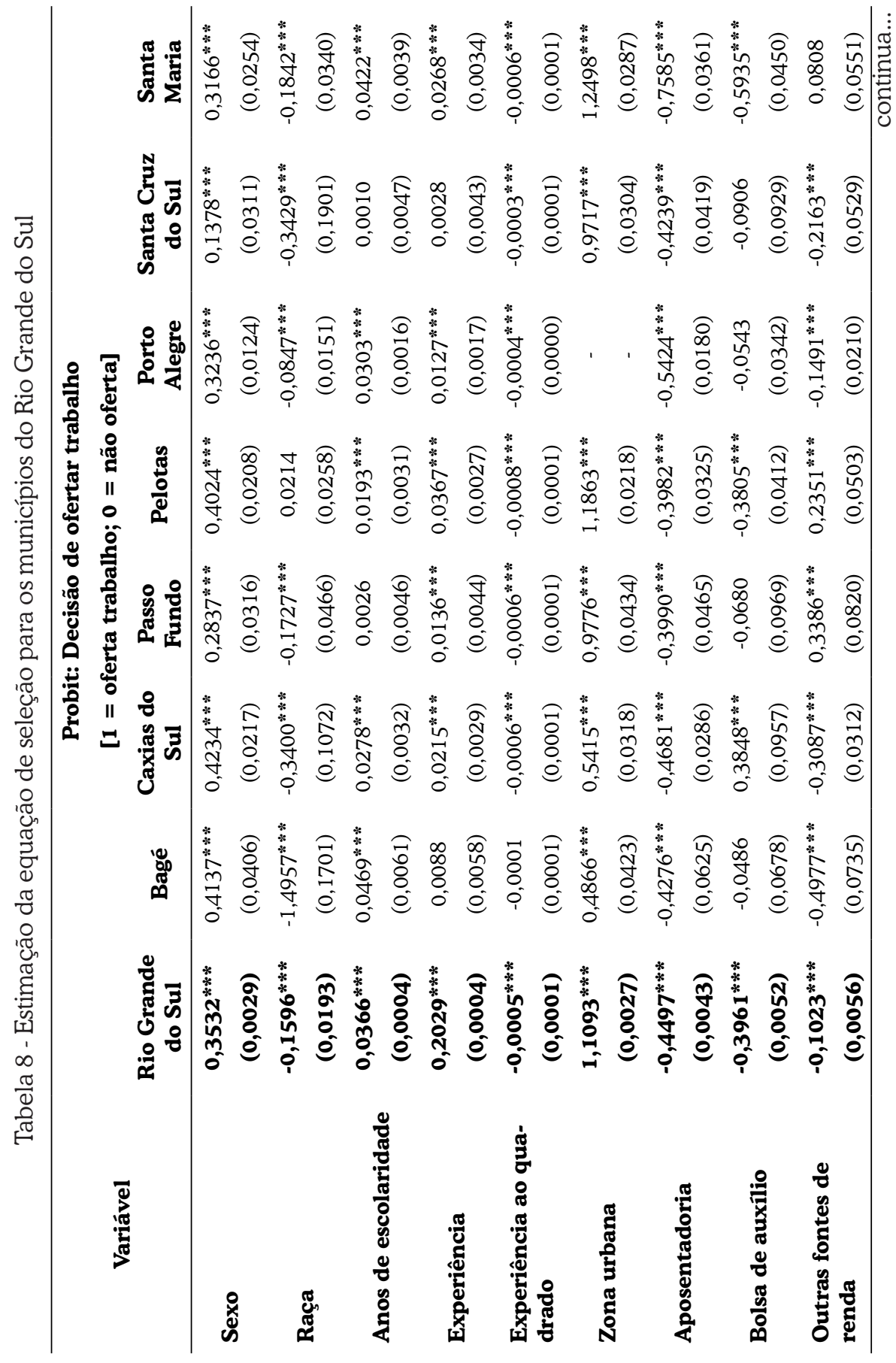




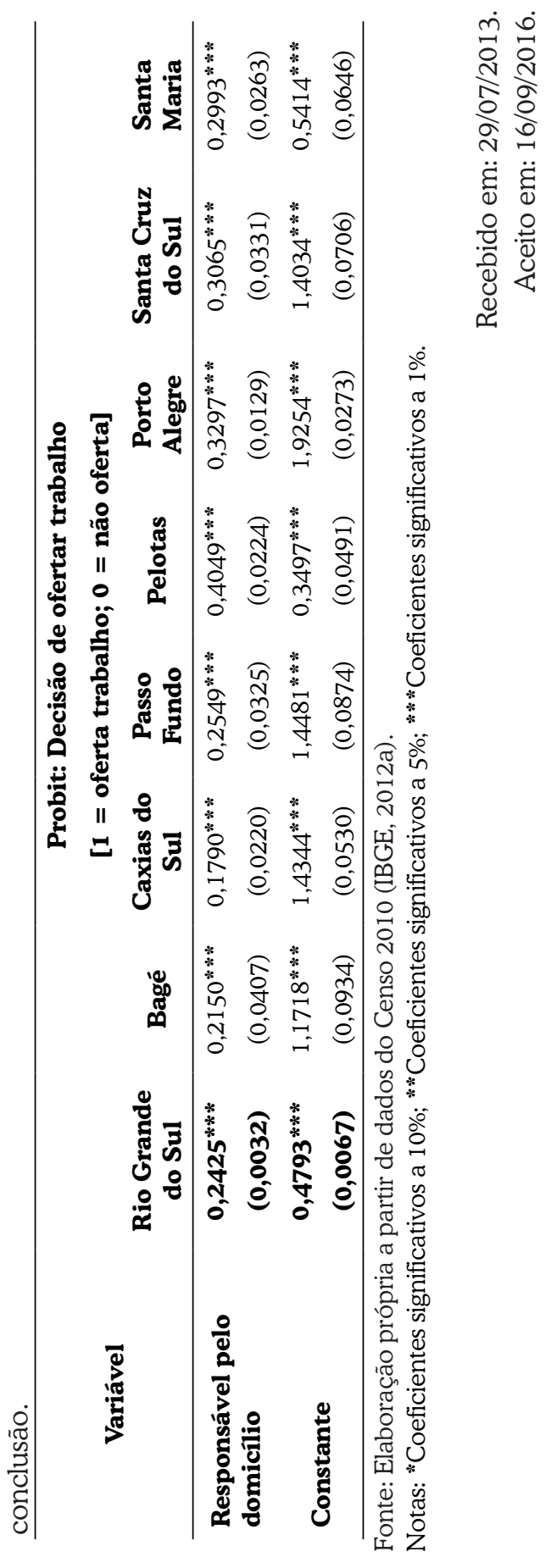

